\title{
The many challenges of increasing Indigenous faculty at medical schools
}

\author{
— Cite as: CMAJ 2019 September 16;191:E1036-7. doi: 10.1503/cmaj.1095792
}

Posted on cmajnews.com on August 28, 2019.

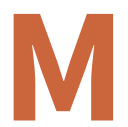

edical schools have committed to increasing Indigenous faculty, which will require education leaders to rethink widespread practices at their institutions, according to Indigenous educators.

Canada's medical schools recently signed on to the Joint Commitment for Action on Indigenous Health. Medical education leaders agreed to "invest in the development of a critical mass of Indigenous faculty and staff with the appropriate supportive infrastructure," and to create a process for identifying and addressing racism experienced by Indigenous faculty.

Dr. Marcia Anderson, chair of the Indigenous Health Network for the Association of Faculties of Medicine (AFMC), said that growing the number of Indigenous medical educators is challenging because Indigenous physicians may have faced racism in previous learning environments, making them hesitant to rejoin academia. Meanwhile, Indigenous health providers often choose to focus on clinical work in underserved communities because they feel that is where they can make the most difference.

Various possibilities have been discussed in AFMC meetings to support a call to action, said Anderson, including the idea of "building a database of Indigenous physicians and health professionals who are potentially interested in academic work." Another idea is to create a speakers bureau of academic Indigenous physicians who could consult at more than one school to "help meet the

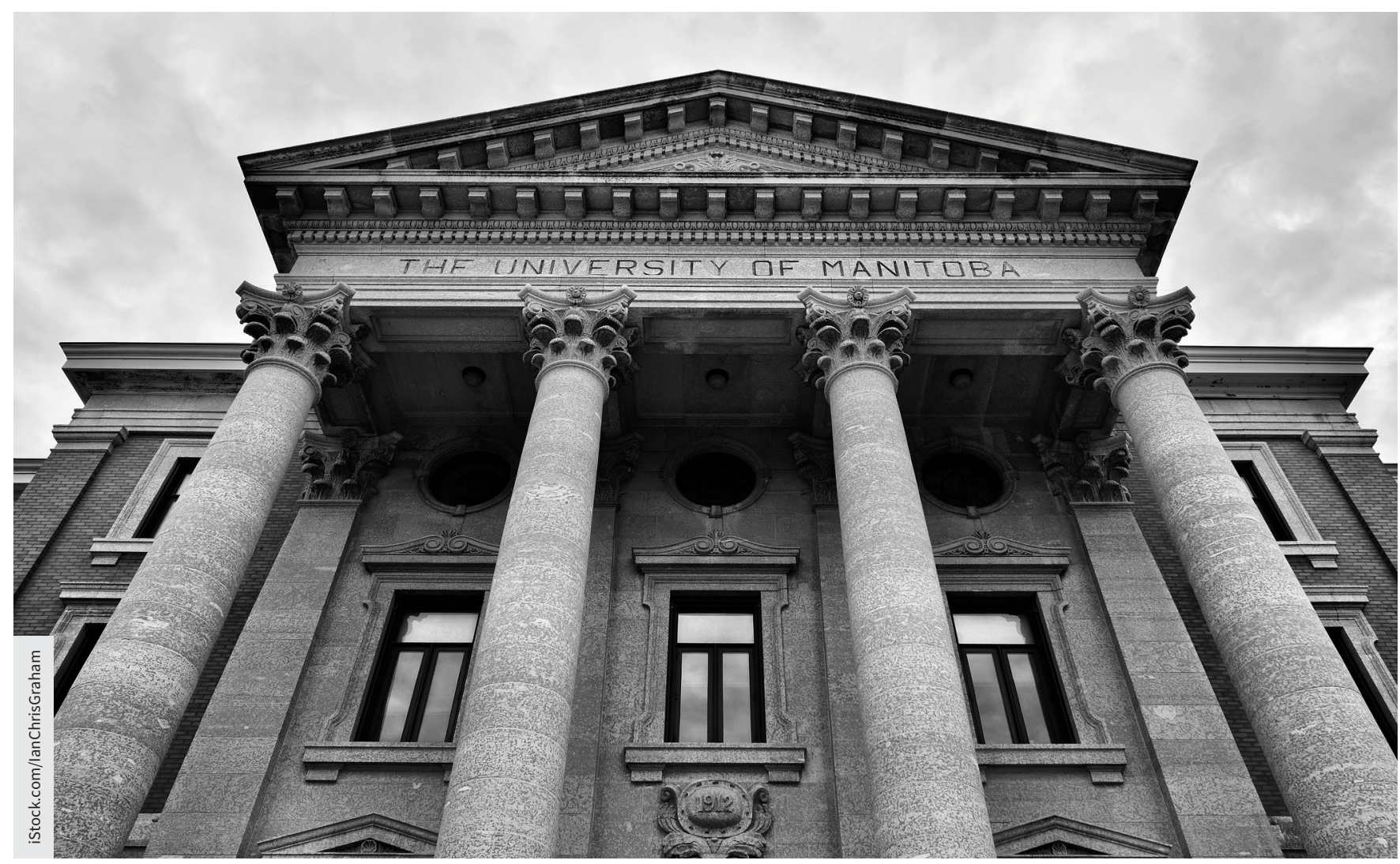

At the University of Manitoba, Indigenous medical educators are paired with non-Indigenous physicians so the work of challenging prejudices doesn't fall only on Indigenous faculty. 
curriculum development and teaching needs, at least on an interim basis."

Faculties of medicine are also recognizing the need to evaluate hiring procedures for bias. Last year, the Northern Ontario School of Medicine released a report on the institution's relationships with Indigenous communities. One of the concerns that spurred the expert review was that the medical school had hired only one fulltime Indigenous faculty member, said Darrel Manitowabi, assistant dean of graduate studies at the school.

"We've really begun to put the spotlight on the hiring issue and think about how unconscious bias may have been at play," said Manitowabi, who added that hiring processes at most institutions are often informed by a Western lens that downplays Indigenous values and ways of knowing.

The expert review recommended that search committees for research, leadership, faculty and staff positions include at least two Indigenous people, that all members of search committees participate in implicit bias training, and that hiring processes include an assessment of the candidate's knowledge of cultural safety and anti-racism.

Dr. Sara Goulet, associate dean of admissions for the Max Rady College of
Medicine at the University of Manitoba, said she has herself experienced biased selection processes. When interviewed for one medical leadership position, for example, she was given feedback that she "told too many stories," which is an important way of conveying information in her Métis culture. "Medical institutions want people to bring their Indigenous values, ways of knowing. And yet when we're interviewed, we're asked questions within a very Western model, which doesn't allow us to shine," she said.

The first step for faculty leaders, according to Manitowabi, is to recognize that prejudice exists in decision-making and learning environments. "The worst environment you can have is one that denies any of this exists." That doesn't mean universities need to take a blameand-isolate approach. "An elder taught me that if someone has racist ideas or discriminatory ideas, they were taught that by someone," he said. Cultural safety training for all students and faculty is key to overcoming harmful stereotypes that both students and faculty may have learned as children, said Manitowabi.

At the University of Manitoba, Indigenous health educators are paired with nonIndigenous physicians so the work of challenging prejudices doesn't fall only on
Indigenous faculty. In addition, the educators are offered frequent debriefing sessions. "We don't want Indigenous educators to feel all alone when they're experiencing racism or have those experiences be discounted or minimized," said Anderson.

Faculties should also facilitate mentorship opportunities and orientation training to retain Indigenous physicians, ideally with other Indigenous leaders, said Goulet. "Physicians coming to academia from a community practice might be intimidated by the policies, processes and procedures within the institution," she explained. "Scheduling orientations, creating a list of mentors, including their interests and expertise, and supporting them through the initial phases of their new roles might help."

Another barrier for physicians coming into academic medicine from the community is the hierarchy that exists within academic institutions, said Goulet. "There is a need to see family medicine, public health and Indigenous health specialists with the same degree of validation for advancement in academic medicine as other specialties if we are going to attract a more diverse group of leaders in academic institutions."

Wendy Glauser, Toronto, Ont. 